\title{
Effect of gelling agents on in vitro development of Amelanchier canadensis 'Rainbow Pillar'
}

\author{
Fira A. ${ }^{1}$, Magyar-Tábori K.*2, Hudák I. ${ }^{2}$, Clapa D. ${ }^{1} \&$ Dobránszki J. ${ }^{2}$ \\ ${ }^{1}$ Fruit Research Station Cluj, Horticultorilor Street no. 5, Cluj-Napoca, Romania \\ ${ }^{2}$ Research Institute of Nyiregyháza, University of Debrecen Centre for Agricultural and Applied Economic \\ Sciences, Research Institute and Study Farm, Nyíregyháza, Westsik u. 4-6., H-4400, \\ Hungarymtaborik@gmail.com
}

\begin{abstract}
Summary: In vitro shoot multiplication responses of Amelanchier canadensis 'Rainbow Pillar' were studied on media solidified with different gelling agents. The media were gelled either with $6.8 \mathrm{~g} \mathrm{l}^{-1}$ fibrous agar-agar, or $50.0 \mathrm{~g} \mathrm{l}^{-1}$ wheat starch, or $20.0 \mathrm{~g} \mathrm{l}^{-1} \mathrm{Guar}_{\text {gum, or } 15 \mathrm{~g} \mathrm{l}^{-1} \text { Isubgol }}$ or $50.0 \mathrm{~g} \mathrm{l}^{-1}$ wheat starch mixed with $0.5 \mathrm{~g} \mathrm{l}^{-1}$ Phytagel. Shoot cultures were grown for two months, thereafter the multiplication rates (number of newly developed shoots per explant) were counted and the length of shoots were measured. We found that the highest shoot multiplication of Amelanchier canadensis 'Rainbow Pillar' occurred on media gelled with Guar gum, while the longest shoots developed on media with Starch. About four-fold shoot number were obtained on media with Guar gum compared to the weakest results found on media gelled with Isubgol. Finally, considering all factors (shoot growth parameters, costs) the most economical gelling agent for Amelanchier canadensis 'Rainbow Pillar' was proved to be wheat starch among the tested alternatives which allows a $75.6 \%$ cost reduction.
\end{abstract}

Key words: Canadian serviceberry, gelrite, guar gum, Isubgol, psyllium, starch

\section{Introduction}

Production of pathogen-free woody propagation material with required genetic properties has worldwide been based on the micropropagation (Kozai \& Kubota, 2001). The price of in vitro propagated plantlets - especially woody plants is relatively high due to the specific technology elements. Each attempt, which results in increased propagation rate, greater rate of high quality plants or decreased loss during acclimatization can reduce the cost of in vitro propagated plantlets (Kozai \& Kubota, 2001). Although liquid medium can be used effectively in automated micropropagation systems (Krueger et al., 1991; Robacker \& Simonton, 1992), the solidification of medium seemed to be necessary in traditional systems, because using of liquid medium resulted in hyperhydric shoots in Amelanchier $x$ grandiflora Rehd. 'Princess Diana' when cultures were continuously in contact with medium (Krueger et al., 1991).

Because of its stability, high clarity, non-toxicity and metabolic inactivity the agar extracted from red algae has been the most frequently used for gelling media (McLachlan, 1985). Even though the cost of medium preparation constitute a small part of the total cost (George, 1996), components of the medium is quite expensive to obtain, especially the plant tissue culture tested agaragar, which has commonly used for woody plants (Kumar Goel et al. 2007). Alternatives including Isubgol (the husk derived from the seeds of Plantago ovata), Guar gum (galactomannan derived from the endosperms of Cyamopsis tetragonoloba), several type of starches (wheat, cassava, corn, potatao, sago etc.) and other additives (bagasse, Xyloglucan extracted from seeds of Hymenaea courbaril etc.) have been studied in several experiments to find a cheaper solution for gelling media (Babbar and Jain, 1998; Naik and Sarkar, 2001; Lima-Nishimura et al., 2003; Mohan et al., 2004; Babbar et al., 2005).

Several blends of agar and its cheap alternatives (guar gum, isubgol and xanthan gum) were evaluated, and none of them had rheological properties comparable to agar gelled medium. However, responses of Albizzia lebbeck tissue culture to majority of blends were the same or even better than the control (agar) (Jain-Raina \& Babbar, 2011). Each types of gelling agents (Plant Agar, Gelcarin GP-812, Guar gum, Isubgol) was effective in micropropagation of blackberry (Rubus laciniatus 'Thornless evergreen'), however the highest multiplication rate was achieved on medium gelled with Plant Agar, while plantlets grown on medium solidified by Guar gum were extremely vigorous and well developed (Fira et al., 2010). Blends of agar and guar increased the number of regenerated shoots in micropropagation of pear (Pyrus communis L., 'Durondeau') compared to media solidified by agar (Lucyszyn et al., 2006).

Mixtures of agar and Isubgol also were effective in in vitro regeneration of potato and Stevia provided that the rate of Isubgol in the mixture does not exceed 50\% (Khan et al., 2012). 
Daud et al. (2011) also tested some starch sources (cassava, rice and corn flour and potato starch) as gelling agents compared to Oxoid technical agar. They found that 60 $\mathrm{g}^{-1}$ cassava flour added to the MS (Murashige and Skoog, 1962) medium resulted in the highest number of regenerated shoots in Celosia sp. Blends of corn or potato starch and agar were also highly effective in potato micropropagation (Mohamed et al., 2010).

The rate of shoot growth during establishment of in vitro shoot culture of walnut was also influenced by the gelling agents; agar, cassava flour and tapioca pearls were added to the initiation media. Albeit significant differences in shoot growth of cultivars ('Mihaela', 'Muscelean' and 'Jupâne ti') were observed, each genotype preferred tapioca pearls as gelling agent (Gotea et al., 2012). Kuria et al. (2008) studied the effect of gelled (agar, cassava starch and their mixture) and liquid media on the fresh weight, number of nodes and survival of micropropagated potato plantlets. They found, that the number of nodes was significantly the lowest on media gelled with agar and the fresh weight was the highest on liquid media, while the survival percentage was higher on gelled media. All parameters considered, media gelled with $10 \%$ cassava starch were proven to be the most effective.

Phytagel enhanced the in vitro tuberization of potato (Arregui et al., 2003) and adventitious bud development in pear (Chevreau et al., 1997), increased the rate of survival during establishment of in vitro culture of Populus trichocarpa (Kang et al., 2009) applied either alone or in combination with agar was also effective in shoot multiplication of Maranta leuconeura (Ebrahim \& Ibrahim, 2000).

In our experiments shoot multiplication responses of Amelanchier canadensis 'Rainbow Pillar' were studied on media gelled with fibrous agar-agar (control), wheat starch, Guar gum, Isubgol and blend of wheat starch and Phytagel.

\section{Materials and methods}

Multiplication of in vitro shoots of Amelanchier canadensis 'Rainbow Pillar' was made on medium containing MS salts (Murashige and Skoog, 1962) and MS vitamins except that vitamin $B_{1}$ was added to the medium at $1.0 \mathrm{mg} \mathrm{l}^{-1}$ instead of 0.1 $\mathrm{mg} \mathrm{l}^{-1}$. The medium was also supplemented with $100 \mathrm{mg} \mathrm{l}^{-1}$ myo-inositol, 3\% sucrose, $6.0 \mathrm{~g} \mathrm{l}^{-1}$ agar-agar and $0.5 \mathrm{mg} \mathrm{l}^{-1}$ 6-benzyladenine (BA). The same medium was used for gelling agent experiments, in which media were gelled with either $6.8 \mathrm{~g}$ $\mathrm{l}^{-1}$ fibrous agar, or $50.0 \mathrm{~g} \mathrm{l}^{-1}$ wheat starch, or $20.0 \mathrm{~g} \mathrm{l}^{-1}$ Guar gum, or $15 \mathrm{~g} \mathrm{l}^{-1}$ Isubgol or a blend of $50.0 \mathrm{~g} \mathrm{l}^{-1}$ wheat starch and with 0.5 $\mathrm{g}^{-1}$ Phytagel. The media were sterilised by ST-124/2 autoclave for $30 \mathrm{~min}$. at $121{ }^{\circ} \mathrm{C}$ and $10^{5} \mathrm{~Pa}$ after adjustment of $\mathrm{pH}$ to 5.8 .

Shoot-tips in $2.0 \mathrm{~cm}$ length were used as explants. Four explants were placed per jar (750 ml Kilner jar) containing 100 $\mathrm{ml}$ medium. Shoot cultures were grown for two months in a growing room at $22^{\circ} \mathrm{C}, 16 \mathrm{~h}$ photoperiod and at a PPF of $105 \mu \mathrm{mol} \mathrm{s}{ }^{-1} \mathrm{~m}^{-2}$. Warm-white lamps (Tungsram F74) were used for illumination of cultures. Each treatment included ten replicates (i.e. 40 explants in total were observed) and experiments were repeated twice in time. After two months the multiplication rates (number of newly developed shoots per explant) were counted and the length of shoots were measured. The data were analysed by ANOVA and Tukey's test was applied as post-hoc test using the SPSS 13.0 for Windows software package.

\section{Results}

Different gelling agents resulted in significant differences in the multiplication rates of Amelanchier canadensis 'Rainbow Pillar' (Figure 1). The most shoots (154.8 per explant) developed on media gelled with Guar gum. Similarly, the multiplication rates were also very high on media contained agar and wheat starch (111.2 and 110.2 new shoots per explant, respectively), while applying Isubgol and Starch+Phytagel mix significantly inhibited the rate of shoot proliferation (34.9 and 65.9 new shoots per explant, respectively) compared to the media with Guar gum. Even when present in small quantities $\left(0.5 \mathrm{~g} \mathrm{l}^{-1}\right)$ the presence of Phytagel inhibited the shoot multiplication of Amelanchier canadensis 'Rainbow Pillar': almost only half of the shoots developed on media containing Starch+ Phytagel (65.9) as gelling agents compared to the media gelled with only starch (110.2). Considering only the usable shoots (larger than $20 \mathrm{~mm}$ ) the best propagation rate also found on the media gelled with Guar gum.

The smallest shoots $(24.0 \mathrm{~mm})$ developed on media containing Isubgol, while the longest shoots grown on media gelled with starch and the mixture of starch and Phytagel (31.5 and $30.8 \mathrm{~mm}$, respectively) (Figure 2). Except for Isubgol, each alternative gelling agent increased significantly the length of shoots compared to the shoot length measured on medium with agar. However, the lengths of newly developed shoots were adequate in each treatment: shoots larger than $20 \mathrm{~mm}$ are suitable for subculture and also for rooting and $e x$ vitro acclimatization.

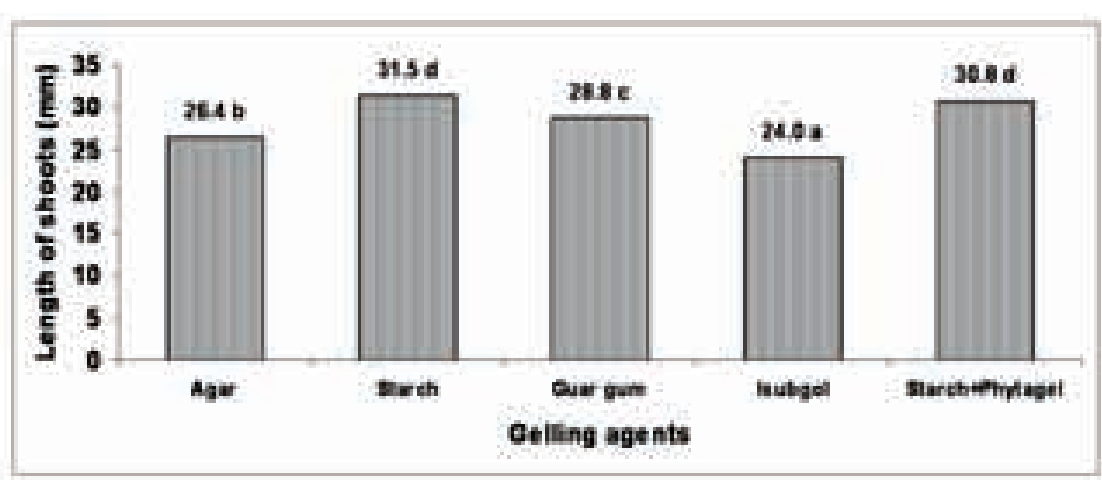

Figure 1. The total numbers of newly developed shoots and numbers of new shoots, longer than $20 \mathrm{~mm}$ on media gelled by different gelling agents. Significant differences $(P \leq 0.05)$ between the media gelled by different gelling agents are indicated by different letters 


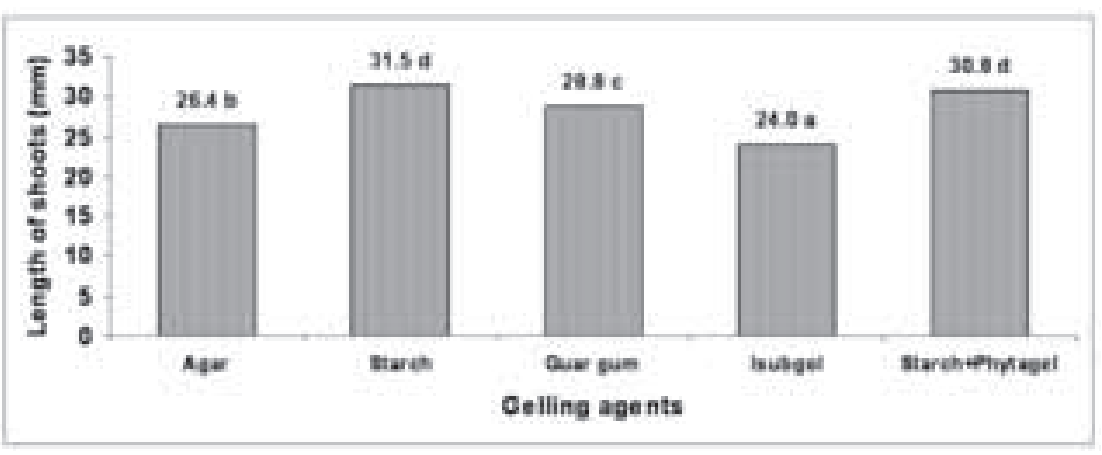

Figure 2. The effect of the gelling agents on the shoot length $(\mathrm{mm})$. Significant differences $(P \leq 0.05)$ between the media gelled by different gelling agents are indicated by different letters. concentration compared to media gelling with agar. Khan et al. (2012) using blends of agar and Isubgol reduced the cost of plant tissue culture medium solidification by $47.5 \%$. However, in our experiments the Isubgol was the least efficient alternative gelling agent resulting in the lowest propagation rate and the smallest shoots of Amelanchier.

Blends of agar and other gelling agents can be effective and cost-saving possibilities (Mohamed et al., 2010; Dobránszki et al., 2011). Ebrahim and Ibrahim (2000) observed

\section{Discussion}

Besides cost reduction adequate hardness of the medium is of importance during plant tissue cultures. If media are too soft the hyperhydricity can be frequent in in vitro cultures while too hard media could result in inhibited growth (Gangopadhyay et al., 2009). In our experiments the physiological states of shoots were adequate for each treatment; no hyperhydrated culture or other physiological disorders were observed, however significant differences were observed in both parameters observed on media gelled differently (Figure 3).

Each tested morphogenic response (seed germination, shoot proliferation, rooting, androgenesis, somatic embryogenesis) was enhanced in in vitro cultures of several plant species (Linum usitatissimum, Brassica juncea, Crataeva nurvala, Nicotiana tabacum, Calliandra tweedii) on media solidified by Guar gum (Babbar et al., 2005). We also observed that the multiplication of shoot cultures of Amelanchier canadensis 'Rainbow Pillar' were the best on media gelled with Guar gum, while the longest shoots developed

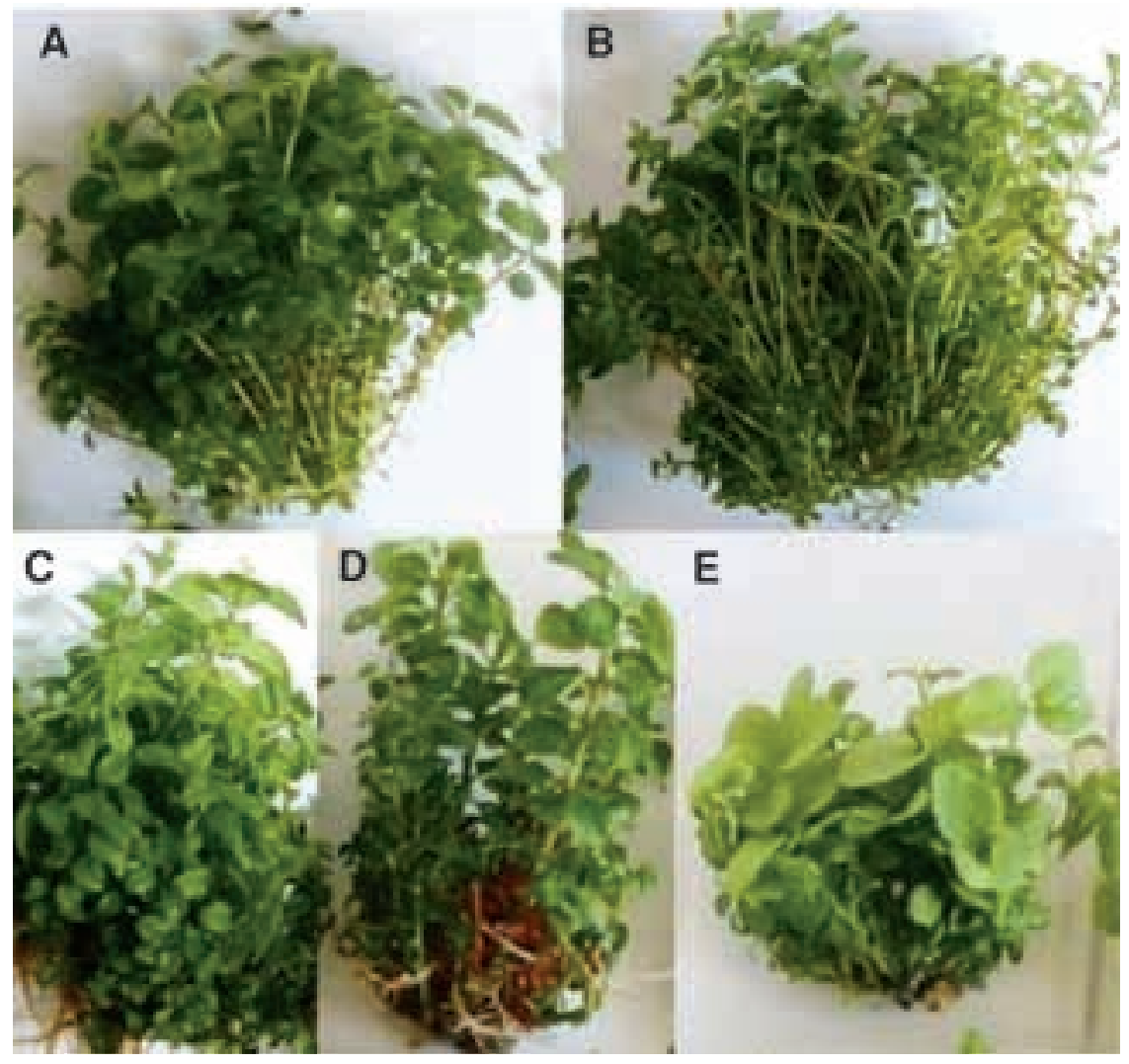

Figure 3. In vitro shoots of Amelanchier canadensis 'Rainbow Pillar' developed on media gelled with either $6.8 \mathrm{~g} \mathrm{l}^{-1}$ fibrous agar-agar (A); or $20.0 \mathrm{~g} \mathrm{l}^{-1}$ Guar gum (B); or $50.0 \mathrm{~g} \mathrm{l}^{-1}$ wheat starch (C); or a blend of $50.0 \mathrm{~g} \mathrm{l}^{-1}$ wheat starch and with $0.5 \mathrm{~g} \mathrm{l}^{-1}$ Phytagel (D); or $15 \mathrm{~g} \mathrm{l}^{-1}$ Isubgol (E). on media with Starch. Stimulating effect of Guar gum was spectacular: more than four-fold shoots were obtained compared to the weakest results found on media gelled with Isubgol. However, the propagation rates found on media gelled with Starch and Guar gum did not differ significantly compared with one another and with the control medium (agar).

One of promising alternatives was Isubgol, because of its low price (Table 1). Babbar and Jain (1998) applying Isubgol obtained that results comparable to agar media in in vitro cultures of Syzygium cuminii and Datura innoxia. In adventitious regeneration experiments with woad (Isatis tictoria) Saglam and Cifici (2010) found more regenerated shoots on media supplemented with Isubgol at $15 \mathrm{~g} \mathrm{l}^{-1}$
Table 1. Comparison of the costs of media gelled with different gelling agents. The gelling agents, used in our experiments marked by *.

\begin{tabular}{|l|c|c|c|}
\hline \multicolumn{1}{|c|}{ Gelling agents } & $\begin{array}{c}\text { Cost per } \\
\mathbf{k g} \\
€\end{array}$ & $\begin{array}{c}\text { Conc. in } \\
\text { medium } \\
(\mathbf{g} / \mathbf{l})\end{array}$ & $\begin{array}{c}\text { Cost per } \\
\text { liter } \\
€\end{array}$ \\
\hline Wheat starch * (commercial) & $1.78 €$ & 50 & 0.089 \\
\hline Wheat starch (Sigma) & $23.90 €$ & 50 & 1.195 \\
\hline Agar-agar * fibrous & $54.05 €$ & 6.8 & 0.368 \\
\hline PTCT $^{1}$ Agar (Sigma) & $593.38 €$ & 5.6 & 3.323 \\
\hline PTCT $^{1}$ Agar (Oxoid) & $124,07 €$ & 5.6 & 0.695 \\
\hline Guar gum * (Sigma) & $110.44 €$ & 20 & 2.209 \\
\hline Phytagel (Sigma) & $413.82 €$ & 2.5 & 1.035 \\
\hline Isubgol * & $15.61 €$ & $15 \mathrm{~g} / 1$ & 0.234 \\
\hline
\end{tabular}

${ }^{1} \mathrm{PTCT}=$ plant tissue culture tested 
that combination of agar and Gelrite $\left(3+1 \mathrm{~g} \mathrm{l}^{-1}\right)$ resulted in the best development and growth of Maranta leuconeura 'Kerchoviana' shoots, but a combination of agar and Gelrite with higher rate of agar $\left(5+0.5 \mathrm{~g}^{-1}\right)$ was superior considering the rooting response of shoots. However, we found in present study that the blend of starch and Phytagel resulted in low number of new shoots similarly to the Isubgol. The presence of Phytagel inhibited only the shoot multiplication, while the mean shoot length was the same on media containing starch alone or combined with Phytagel. Ivanova et al. (2007) also observed that in vitro shoot cultures of Aloe polyphylla did not respond well to Gelrite; the propagation rate was lower and the hyperhydrated cultures were more frequent on medium gelled with Gelrite compared to medium containing agar. When the concentration was increased from 2.4 up to $16 \mathrm{~g} \mathrm{l}^{-1}$ the rate of hyperhydricity was reduced but the number of shoot also decreased (Ivanova and Van Staden, 2011).

Although the highest number of new shoots was achieved on medium containing Guar gum, applying the wheat starch for gelling medium was proved to be the most effective for Amelanchier canadensis 'Rainbow Pillar'; the propagation rate was similar to the control (agar) medium, and the shoots were the longest. Moreover, the cost of wheat starch is the best among tested alternatives: the price of commercial wheat starch is a very small proportion of the price of agar, even the pure wheat starch (Sigma) price is only half of the price of agar (Table 1). Cassava starch was found to be the most effective for Celoisa sp. (Daud et al., 2011) and Kuria et al. (2008) also used it for potato propagation at $10 \%$ in medium and reduced cost by $42.5 \%$ compared to medium gelled by agar. Corn and potato starch were also usable gelling agents in combination with Gelrite in Musa 'Grande Naine' shoot tip culture, moreover $90 \%$ cost reduction was achieved when sucrose source was also replaced by commercial sugars (Kodym and Zapata-Arias, 2001).

Table 2. Comparison of the economy of media solidified with different gelling agents

\begin{tabular}{|l|c|c|c|c|}
\hline \multicolumn{1}{|c|}{ Gelling agents } & $\begin{array}{c}\text { Cost per } \\
\text { liter } \\
€\end{array}$ & Yield* & $\begin{array}{c}\text { Cost of } \\
\text { gelling } \\
\text { per new } \\
\text { shoots } \\
\text { x } 10^{-4} €\end{array}$ & $\begin{array}{c}\text { Changes } \\
\text { in the } \\
\text { cost of } \\
\text { gelling } \\
(\%)\end{array}$ \\
\hline $\begin{array}{l}\text { Wheat starch* } \\
\text { (commercial) }\end{array}$ & 0.089 & 4408 & 0.2019 & $-75.6 \%$ \\
\hline Agar-agar * fibrous & 0.368 & 4448 & 0.827 & 0 \\
\hline Guar gum * (Sigma) & 2.209 & 6192 & 3.57 & $+331 \%$ \\
\hline $\begin{array}{l}\text { Wheat starch * } \\
\text { (commercial) + Phytagel }\end{array}$ & 0.296 & 2636 & 1.123 & $+35.8 \%$ \\
\hline Isubgol * & 0.234 & 1396 & 1.68 & $+103.1 \%$ \\
\hline * The number of newly developed shoots using 1 1 medium (counting from \\
propagation rates, which can be realised on the medium in the case of four \\
explants on 100 ml medium)
\end{tabular}

The cost of Guar gum is relatively high (Table 1) and when added to the media alone, at least $20 \mathrm{~g}^{1^{-1}}$ was necessary to obtain medium with appropriate consistency. In this case the cost of medium is high. However, Dobránszki et al. (2011) used blend of Guar gum and agar for micropropagation of apple and black locust effectively, about $42 \%$ cost reduction could be achieved.

Considering all factors examined, such as propagation rates, shoot lengths, media costs, cost per plantlets, the most effective gelling agent for Amelanchier canadensis 'Rainbow Pillar' is the wheat starch among the tested alternatives. Although a very cheap agar-agar (fibrous) was selected as control, which in itself was a cost reduction, we could reach further cost reduction applying wheat starch $(75.6 \%$ cost reduction could be reached considering only the gelling of the medium) (Table 2).

\section{References}

Arregiu L. M., Veramendi J. \& Mingo-Castel A. M. (2003): Effect of gelling agents on in vitro tuberisation of six potato cultivars. American Journal of Potato Research, 80: 141-144.

Babbar S. B. \& Jain N. (1998): 'Isubgol' as an alternative gelling agent in plant tissue culture media. Plant Cell Reports, 17: 318-322.

Babbar S. B., Jain R. \& Walia N. (2005): Guar gum as gelling agent for plant tissue culture media. In Vitro Cellular \& Developmental Biology - Plant, 41: 258-261.

Chevreau E., Mourgues F., Neveu M. \& Chevailer M. (1997): Effect of gelling agents and antibodies on adventitious bud regeneration from in vitro leaves of pear. In Vitro Cellular \& Developmental Biology - Plant, 33: 173-179.

Daud N., Taha R. M., Noor N. N. M. \& Alimor H. (2011): Potential of alternative gelling agents in media for the in vitro micro-propagation of Celosia sp. International Journal of Botany, 7 (2): 183-188.

Dobránszki J., Magyar-Tábori K. \& Tombácz E. (2011): Comparison of the rheological and diffusion properties of some gelling agents and blends and their effects on shoot multiplication. Plant Biotechnology Reports, 5: 345-352.

Ebrahim M. K. H. \& Ibrahim I. A. (2000): Influence of medium solidification and $\mathrm{pH}$ value on in vitro propagation of Maranta leuconeura cv. Kerchoviana. Scientia Horticulturae, 86: 211-221.

Fira A., Clapa D. \& Plopa C. (2010): New aspects regarding the micropropagation of blackberry cultivar 'Thornless evergreen'. Bulletin UASVM Horticulture, 67 (1): 106-114.

Gangopadhyay G., Roy S. K. and Mukherjee K. K. (2009): Plant response to alternative matrices for in vitro root induction. African Journal of Biotechnology, 8 (13): 2923-2928.

George E. F. (1996): Commercial Micropropagation. The Economics of production. In: Plant Propagation by Tissue Culture part 2, In practice. Exegetics Limited. pp. 761-786.

Gotea R., Sheikh Beig Goharizzi M. A., Gotea I., Ziaee M., Farsi M., Sestras R. E. \& Vahdati K. (2012): The in vitro Establishment of Walnut (J. regia L.) by Using two Alternative Gelling Agents first Results. Bulletin UASVM Horticulture, 69 (1): 392-394.

Ivanova M., Novák O., Strnad M. \& Van Staden J. (2006): Endogenous cytokinins in shoots of Aloe polyphylla cultured in vitro in relation to hyperhydricity, exogenous cytokinins and gelling agents. Plant Growth Regulation, 50: 219-230.

Ivanova M. \& Van Staden J. (2011): Influence of gelling agent and cytokinins on the control of hyperhydricity in Aloe polyphylla. Plant Cell, Tissue and Organ Culture, 104:13-21. 
Jain-Raina R. \& Babbar S. B. (2011): Evaluation of blends of alternative gelling agents with agar and development of xanthagar, a gelling mix suitable for plant tissue culture media. Asian Journal of Biotechnology, 3 (2): 153-164.

Kang B., Osburn L., Kopsell D., Tuskan G. A. \& Cheng Z. M. (2009): Micropropagation of Populus trichocarpa 'Nisqually-1': the genotype deriving the Populus reference genome. Plant Cell, Tissue and Organ Culture, 99: 251-257.

Khan S., Al Marufb A., Aktera S., Habiba A., Tanjina Akhtar Banua T. A. \& Islama S. (2012): Admixture of Isubgol husk together with conventionally used agar as gelling agent for Potato and Stevia regeneration. Bangladesh Journal of Scientific and Industrial Research, 47 (2): 161-166.

Kodym A. \& Zapata-Arias F. J. (2001): Low-cost alternatives for the micropropagation of banana. Plant Cell, Tissue and Organ Culture, 66: 67-71.

Kozai T. \& Kubota C. (2001): Developing a Photoautotrophic Micropropagation System for Woody Plants. Journal of Plant Research, 114: 525--537.

Krueger S., Robacker C. \& Simonton W. (1991): Culture of Amelanchier $x$ grandiflora in a programmable micropropagation apparatus. Plant Cell, Tissue and Organ Culture, 27 (2): 219-226.

Kuria P., Demo P., Nyende A. B. \& Kahangi, E. M. (2008): Cassava starch as an alternative cheap gelling agent for the in vitro micro-propagation of potato (Solanum tuberosum L.). African Journal of Biotechnology, 7 (3): 301-307.

Lima-Nishimura N., Quoirin M., Naddaf Y. G., Wilhelm H. M., Ribas L. L. F. \& Sierakowski M-R. (2003): A xyloglucan from seeds of the native Brazilian species Hymenaea courbaril for micropropagation of Marubakaido and Jonagored apples. Plant Cell Reports, 21: 402-407.

Lucyszyn N., Quoirin M., Riba L. L. F, Koehler H. S. \& Sierakowski M. R. (2006): Micropropagation of 'Durondeau' pear in modified-gelled medium. In Vitro Cellular \& Developmental Biology - Plant, 42: 287-290.

McLachlan J. (1985): Microalgae (sea weeds): industrial sources and their utilization. Plant Soil, 89: 137-157.

Mohamed M. A. H., Alsadon A. A. \& Al Mohaidib M. S. (2010): Corn and potato starch as an alternative for Solanum tuberosum micropropagation. African Journal of Biotechnology, 9 (1): 012-016.

Mohan R., Soccol C. R., Quoirin M. \& Pandey A. (2004): Use of sugarcane bagasse as an alternative low-cost support material during the rooting stage of apple micropropagation. In Vitro Cellular and Developmental Biology-Plant, 40: 408-411.

Murashige T. \& Skoog F. (1962): A revised medium for rapid growth and bioassays with tobacco tissue cultures. Physiologia Plantarum, 15: 473-497.

Naik P. S. \& Sarkar D. (2001): Sago: an alternative cheap gelling agent for potato in vitro culture. Biologia Plantarum, 44 (2): 293-296.

Robacker C. D. \& Simonton W. (1992): Development of a computer-controlled apparatus for micropropagation studies. Acta Horticulturae, 319: 585-590.

Saglam S., \& Cifici C. Y. (2010): Effects of agar and 1subgol on adventitous shoot regeneration of woad (Isatis tinctoria). International Journal of Agriculture \& Biology, 12: 281-285. 